\title{
Involvement of family environmental, behavioral, and social functional factors in children with attention-deficit/hyperactivity disorder
}

This article was published in the following Dove Press journal:

Psychology Research and Behavior Management

\author{
Yanhong Huang' \\ Haiyun $\mathrm{Xu}^{\prime}$ \\ William $\mathrm{Au}^{2,3}$ \\ Chongtao $\mathrm{Xu}^{\prime}$ \\ Kusheng $\mathrm{Wu}^{2}$
}

'Mental Health Center, Shantou

University Medical College,

Shantou, People's Republic of China;

${ }^{2}$ Department of Preventive Medicine,

Shantou University Medical College,

Shantou, People's Republic of China;

${ }^{3}$ Institute of Advanced Studies,

University of Medicine and Pharmacy,

Tirgu Mures, Romania
Correspondence: Kusheng Wu

Department of Preventive Medicine,

Shantou University Medical College,

Xinling Road, Shantou 5I504I,

Guangdong Province, People's Republic

of China

Tel +8675488900445

Fax +8675488557562

Email kswu@stu.edu.cn

Chongtao Xu

Mental Health Center, Shantou University

Medical College, North Taishan Road,

Shantou 5I5065, Guangdong Province,

People's Republic of China

Tel +8675488900598

Email xu_chongtao@139.com
Background: The objective of this study was to investigate relationships among family environmental characteristics, behavior problems, and social function impairments in children with ADHD.

Methods: Among children from four primary schools in Shantou city of China, 132 who were diagnosed with ADHD were selected and 138 typically developing children were recruited from the same schools. These children were evaluated using the self-designed questionnaire, FES-CV, CPRS, CTRS, and WFIRS-P for familial environment, behavioral problems, and social function impairment measures. In addition, children's behavioral problems and functional impairments were evaluated using self-established field behavior observation method. Logistic regression model was used to estimate ORs and 95\% CIs for ADHD risk with family environmental factors.

Results: In the unconditional logistic model, ADHD risk in children was increased with parents' worse educational level, occupational status, and emotional stability with trend. Children with ADHD had lower scores on most subscales of FES-CV $(P<0.01)$ but higher scores on Conflict subscale $(P<0.001)$. Children with ADHD showed impairments on all the six WFIRS-P subscales tests (all $P<0.001$ ), and higher scores on the CPRS and CTRS scale subscales representing behavioral symptoms (all $P<0.001$ except Somatic Complaints), and more behavioral problems and functional impairments.

Conclusion: Compared with typically developing children, children with ADHD had worse family environment. Family characteristics especially parents' emotional unstability, lower education levels, and worse occupation status may increase ADHD risk in children. In addition, the behavioral problems and social functional impairments may interact with adverse family environmental factors in children with ADHD. Therefore, early interventions with focus onto the compromising factors can be useful for improving the social-behavioral functions of children with ADHD.

Keywords: ADHD, primary school children, family characteristics, social functional impairment, behavior problems

\section{Background}

ADHD is the most common neurobehavioral disorder in children. ADHD is characterized by having developmentally impaired levels of hyperactivity, impulsivity, and/ or inattention. ${ }^{1}$ The incidence of ADHD in boys is 2-3 times more than in girls. ${ }^{2}$ The prevalence according to the criteria of DSM-5 is around 6\% in China as well as in Shantou city. ${ }^{3}$ 
Social functional impairment is a serious concern among children with ADHD. Social function refers to possessing the social, emotional, and intellectual skills and behaviors which are needed to interact positively with others. Social functional impairment includes several aspects such as executive-functional deficits, bad school performance, and bad social interactions. ${ }^{4}$ Some clinical studies have shown that these symptoms and impairment of ADHD were variable and would continue in older ages. ${ }^{5}$ Consequently, ADHD would persist into late teenage years and even adulthood, which would result in many emotional and conduct problems. As a chronic and permanent disease, the highest prevalence of ADHD is in the school-age children. With increase in age, hyperactivity level would fall but other symptoms would persist into adulthood in as many as $65 \%-75 \%$ of the children. ${ }^{6}$ In adulthood, these individuals would easily develop a variety of emotional disorders, personality disorders, and substance abuse, resulting in extensive and negative impact to families and societies. ${ }^{7}$

ADHD in children would influence their academic achievements and interpersonal relationships, leading to low selfesteem, low self-evaluation, and negative emotions. ${ }^{8,9}$ Academic and social functions of these children are significantly lower than those of other children. However, they display obvious heterogeneity, with some of them developing more serious academic and social impairment over time..$^{10}$ In China, children face academic pressure since their primary schooling. Under these conditions, whether the academic achievements and social function including executive function, school performance, and social interactions among the children with ADHD would be seriously impaired is an urgent issue to be addressed. Furthermore, ADHD in childhood would develop later working disability in mid-adulthood compared with other internalizing and externalizing disorders. ${ }^{11}$ Therefore, ADHD is a serious medical problem for the affected children and for their families.

ADHD is a complex disease which is influenced by genetic and environmental factors. ${ }^{12-14}$ Except for the biological underpinnings of ADHD, it is well known that ADHD is related to social factors such as lifestyles of the parents, parents' education levels, parents' absence from the family, and how these children were raised. ${ }^{15}$ Although family factors may not be the key mechanism for causation of ADHD, their presence affects the entire process of the disease. ${ }^{16}$ Therefore, good behavioral patterns need to be set up in a stable and healthy family environment for these children. For example, ineffective, inconsistent, and negligent parenting were associated with aggravating the symptoms of ADHD, including disruptive behavioral disorders, such as Conduct
Disorder. On the other hand, children with more positive and involving parents showed an improvement of symptoms. ${ }^{17}$ Other family environments, such as lower SES and nontraditional single-parent families, were associated with increased ADHD incidence. ${ }^{18,19}$ Lower SES was also associated with adverse prenatal conditions, unhealthy lifestyles, and lower core family values which would create an unhealthy growth environment for children and put them at risk for more behavior problems or ADHD symptoms. ${ }^{11}$

However, how these family environmental and social factors would affect behaviors of these children and/or what kinds of behaviors would be affected by them have not been adequately investigated. In addition, whether the family environmental factors would play vital roles in the recovery of social function impairment is unknown. Therefore, our study was focused on using the Family Status Questionnaire and FES-CV to investigate the family environmental factors; and using the CPRS, CTRS, WFIRS-P, and field observation methods to evaluate the behavioral characteristics and social functional impairments of children with ADHD. The collected data were used to investigate their interrelationships and to provide scientific basis for clinical diagnosis and treatment of ADHD.

\section{Methods}

\section{Study populations}

From September 2013 to April 2014, children who met the diagnostic criteria of DSM-5 for ADHD were screened out from four stratified sampling primary schools in Shantou and were recruited for participation in our study. As controls, typically developing children from these same schools were randomly selected and matched according to gender and age to the cases. A two-stage screening procedure to diagnose children with ADHD was described in detail in our previous publication, ${ }^{3}$ and shown in Figure S1. Children with major physical diseases, bipolar disorder, psychotic disorder, and other severe psychiatric disorders were excluded. According to DSM-5, ${ }^{1}$ the final diagnosis of the children with ADHD was in accordance with the criteria of six (or more) of the inattention or hyperactivity and impulsivity symptoms; the disease had lasted for 6 months or more before the age of 12 ; the symptoms were found on multiple occasions (eg, school and family); there were obvious functional impairments; and the symptoms were not caused by other mental disorders. Those who were suspected as mental retardation (generalized developmental disorders) were excluded by the Wechsler intelligence test. Our survey was approved by the ethics committee of Shantou University Medical College (Ref No.: 
SUMC-2014XM-0021) and written informed consents were obtained from participants and guardians prior to the study.

\section{General demographic and family characteristics}

The self-designed questionnaire was used to obtain basic demographic information and family characteristics or status including date of birth, gender, family members, parents' occupation, parents' educational levels, family type, family income, mother health during pregnancy, mother's emotional stability during pregnancy, delivery situation, growth and development situation, family history of ADHD and history of other diseases, parents' education manner, etc. The questionnaire was answered by the parents.

\section{FES-CV}

FES-CV was used for family environmental factors investigation, including 90 items of 10 dimensions: cohesion, expressiveness, conflict, independence, achievement, intellectual-cultural, active-recreational, moral-religious, organization, and control. ${ }^{20}$ Each item was answered by parents as "Yes=1" or "No=2." Presently, it is usually used to evaluate different kinds of families in China; and also can test family relationships and family environment changes before and after the family therapy. The FES-CV has widely been used with good reliability and validity. The Cronbach's $\alpha$ of this scale is 0.903 in this study.

\section{CPRS and CTRS}

Conners' Children Behavior Scale is the most widely used scale for screening of ADHD, which includes Conners' ASQ, CPRS, and CTRS. ${ }^{20-22}$

In the present study, CPRS was used to assess children's behavioral problems by parents. The 1978 s revision includes 48 items of six factors: conduct problem, learning problem, somatic complaints, hyperactivity, anxiety, and CIH. Each item ranged from 0, not true at all, to 3 , exactly true $(0,1,2,3)$. The scale basically summed up the common behavior problems of children, and its reliability and validity were tested. This scale has a Cronbach's $\alpha$ of 0.912 in this study.

CTRS was used to assess the behavior of children by teachers. The 1978 s revision includes 28 items of four factors: conduct problem, hyperactivity, inattention, and CIH. The rating method was the same as CPRS. The reliability and validity of this questionnaire were also tested, with a Cronbach's $\alpha$ of 0.907 in this study.

\section{WFIRS-P}

WFIRS-P was a rating scale for evaluating social function of children with ADHD. ${ }^{23,24}$ The WFIRS-P contained 50 items organized into the functional domains of Family, Child's Self-Concept, Learning \& School, Social Activities, Life Skills, and Risky Activities, with possible responses to items using a four-point Likert scale $(0=$ Never or not at all, $3=$ Very often or very much). In each subscale, two or more item scores $\geq 2$, one item score of 3 , or a mean score $>1.5$ would indicate impairment. The Chinese version has good reliability and validity. ${ }^{25}$ The scale has a Cronbach's $\alpha$ of 0.897 in this study.

\section{FBOL}

The FBOL was established by the authors based on our previous investigation in the primary schools, with reference to the 18-symptom items of DSM-5 diagnostic criteria for ADHD. This 12-items behavior rating list was used for field assessments of behavioral problems and function impairment in children by professionals.

\section{Statistical analyses}

Statistical analyses involved use of Epidata 3.0 and SPSS 23.0 (IBM Corporation, Armonk, NY, USA). Categorical data were presented as number (percentages) and continuous data as mean $\pm \mathrm{SD}$. Normal distribution tests were verified by using Kolmogorov-Smirnov and Shapiro-Wilk statistics. Independent-samples $t$-test and one-way ANOVA were used to compare scores for variables normally distributed. Pearson correlation analysis was used to evaluate whether dimensions of CPRS and CTRS were correlated with each other. A univariate logistic regression model was used to estimate ORs and 95\% CIs for ADHD risk with family environmental factors. We calculated $P$-values for trend from the CochranMantel-Haenszel chi-squared test. A two-sided $P<0.05$ was considered statistically significant.

\section{Results General characteristic of the participated children}

Of the 175 recruited children who were diagnosed with ADHD, 132 (75.4\%) completed all the questionnaires and tests, including 100 boys (75.8\%) and 32 girls (24.2\%). The participation rate was $75.4 \%$. In addition, 98 (71.0\%) boys and 40 girls $(29.0 \%)$ of typically developing children also finished the same questionnaires and tests. There were no 
significant differences in the sex ratio and age of the two groups (both $P>0.05$; Table 1).

\section{Comparison of family characteristics between the ADHD and control groups}

The proportion of parents who had educational levels of junior college, bachelor degree, or above was lower in ADHD group than that in the control group (both father and mother;
$P<0.001$ ), while the proportion of low education level was higher (both father and mother; $P<0.001$ ). In occupational status, more parents in the control groups were professional technicians and civil servants but a large proportion of parents with ADHD children were company employees, engaged in business/service industries, or unemployed $(P<0.001$; Table 1). Proportions of unstable emotion in parents, and of hyperactivity/impulsivity in parents' childhood, were higher in

Table I Family characteristics between the ADHD $(n=132)$ and the control $(n=138)$ groups

\begin{tabular}{|c|c|c|c|c|}
\hline Characteristics & ADHD, N (\%) & Control, N (\%) & $t / \chi^{2}$ & $P$-value \\
\hline Age (mean $\pm S D)$ & $9.28 \pm 1.39$ & $9.26 \pm 1.52$ & 0.11 & 0.910 \\
\hline Sex & & & 0.78 & 0.380 \\
\hline Male & $100(75.8)$ & $98(71.0)$ & & \\
\hline Female & $32(24.2)$ & $40(29.0)$ & & \\
\hline Father's education level & & & 40.92 & $<0.001$ \\
\hline Bachelor degree or above & $37(28)$ & $74(53.6)$ & & \\
\hline Junior college & $26(19.7)$ & $37(26.8)$ & & \\
\hline High school & $44(33.3)$ & $26(18.8)$ & & \\
\hline Junior high school or below & $25(19)$ & I (0.7) & & \\
\hline Father's occupation & & & 35.70 & $<0.001$ \\
\hline Technical personnel & $17(12.9)$ & $37(26.8)$ & & \\
\hline Civil servants & $12(9.1)$ & $38(27.5)$ & & \\
\hline Business/service industries & $32(24.2)$ & $19(13.8)$ & & \\
\hline Company employees & $26(19.7)$ & $26(18.8)$ & & \\
\hline Unemployed & $45(34.1)$ & $18(13.0)$ & & \\
\hline Father's emotional stability & & & 11.70 & 0.001 \\
\hline Stable & III (84.I) & $133(96.4)$ & & \\
\hline Unstable & $21(15.9)$ & $5(3.6)$ & & \\
\hline Mother's education level & & & 36.40 & $<0.001$ \\
\hline Bachelor degree or above & $27(20.5)$ & $40(29.0)$ & & \\
\hline Junior college & $37(28)$ & $72(52.2)$ & & \\
\hline High school & $38(28.8)$ & $21(15.2)$ & & \\
\hline Junior high school or below & $30(22.8)$ & $5(3.6)$ & & \\
\hline Mother's occupation & & & 48.35 & $<0.001$ \\
\hline Technical personnel & $14(10.6)$ & $64(46.4)$ & & \\
\hline Civil servants & $8(6.1)$ & $12(8.7)$ & & \\
\hline Business/service industries & $23(17.4)$ & $12(8.7)$ & & \\
\hline Company employees & $27(20.5)$ & $22(15.9)$ & & \\
\hline Unemployed & $60(45.5)$ & $28(20.3)$ & & \\
\hline Mother's emotional stability & & & 5.24 & 0.020 \\
\hline Stable & $112(84.8)$ & $129(93.5)$ & & \\
\hline Unstable & $20(15.2)$ & $9(6.5)$ & & \\
\hline Family type & & & $3.80^{\mathrm{a}}$ & 0.16 \\
\hline Core family & $68(51.5)$ & $60(43.5)$ & & \\
\hline Big family of multi-generation & $59(44.7)$ & $76(55.1)$ & & \\
\hline $\begin{array}{l}\text { Other (single parent, } \\
\text { reorganization) }\end{array}$ & $5(3.8)$ & $2(1.4)$ & & \\
\hline \multicolumn{5}{|l|}{ Family history } \\
\hline Poor intelligence and poor & $2(1.5)$ & 0 & & \\
\hline living ability & & & & \\
\hline Hyperactivity/impulsivity & $15(11.4)$ & $4(2.9)$ & $7.39^{\mathrm{a}}$ & 0.007 \\
\hline Learning difficulty & $23(17.4)$ & $\mathrm{I}(0.7)$ & $23.23^{\mathrm{a}}$ & $<0.001$ \\
\hline Short fuse/oddball/impulsivity & $14(10.6)$ & $\mathrm{I}(0.7)$ & $12.56^{\mathrm{a}}$ & $<0.001$ \\
\hline Substance abuse & $2(1.5)$ & $0(0.0)$ & & \\
\hline
\end{tabular}

Note: 'Fisher's exact test.

Abbreviation: ADHD, attention-deficit/hyperactivity disorder. 
the ADHD group than that in the control group (both $P<0.01$ ). There was no significant difference in family types between the two groups $(P=0.16)$. In addition, parental childhood history of naughty, hyperactivity, learning difficulties, poor grades, bad-tempered, eccentric, impulsive behavior, and substance abuse were higher in the ADHD group $(P<0.01$; Table 1). Interestingly, $10 \%-20 \%$ of parents' performance during childhood was similar to that of their children, and more than $15 \%$ of the parents were emotionally unstable.

Unconditional logistic regression analysis was used to estimate ORs and 95\% CIs for ADHD risk associated with family environmental factors. For mother's occupation, ADHD risk was increased in company employee and the unemployed as compared with technical personnel (OR $[95 \% \mathrm{CI}]=2.34$ [1.40-8.01], 5.91 [2.16-16.17], respectively). With regard to mother's educational level, the ADHD risk increased with the decrease in educational level (OR [95\% CI] $=1.17$ [0.49-2.83], 8.81 [2.23-34.83], 9.21 [1.25-67.62], respectively; Table 2). The results were also similar for father's occupation and education level. In addition, parents' emotional stability was also important factors contributing ADHD risk. Unstable emotion can also increase ADHD risk; OR (95\% CI) was 1.73 (1.01-3.01) for mother and 1.83 (1.28-6.28) for father (Table 2). Family type was not an independent factor for ADHD risk in this study.

\section{Comparison of family environmental factors}

Results from the FES-CV investigation show that the ADHD group's cohesion, expressiveness, independence, achievement, intellectual-cultural, active-recreational, moral-religious, and organization and control scores were lower than that of the control group, while the Conflict score was higher than the control group (all $P<0.01$; Figure 1). There was no significant difference between the different age groups (data not shown).

\section{CPRS and CTRS}

CPRS test results show that the scores of conduct problem, learning problem, hyperactivity, anxiety, and CIH of the ADHD group were higher than those of the control group (all $P<0.001$; Figure 2A). However, somatic complaints score was

Table 2 Multivariate logistic regression analyses of family environmental factors associated with ADHD risk

\begin{tabular}{|c|c|c|c|c|c|}
\hline Variables & B & Wald & $P$-value & OR $(95 \% \mathrm{CI})$ & $P$ for trend \\
\hline \multicolumn{6}{|l|}{ Mother's occupation } \\
\hline Technical personnel & & & & I.00 (Ref) & $<0.001$ \\
\hline Civil servants & -0.105 & 0.032 & 0.857 & $0.90(0.29-2.82)$ & \\
\hline Business/service industries & 0.807 & 3.459 & 0.063 & $2.24(0.96-5.24)$ & \\
\hline Company employees & 1.207 & 7.343 & 0.007 & $2.34(1.40-8.01)$ & \\
\hline Unemployed & 1.777 & 11.969 & 0.001 & $5.91(2.16-16.17)$ & \\
\hline \multicolumn{6}{|l|}{ Mother's education level } \\
\hline Bachelor degree or above & & & & $\mathrm{I} .00$ (Ref) & $<0.001$ \\
\hline Junior college & 0.157 & 0.123 & 0.726 & $1.17(0.49-2.83)$ & \\
\hline High school & 2.18 & 9.629 & 0.002 & $8.81(2.23-34.83)$ & \\
\hline Junior high school or below & 2.22 & 4.764 & 0.029 & $9.21(1.25-67.62)$ & \\
\hline \multicolumn{6}{|l|}{ Father's occupation } \\
\hline Technical personnel & & & & $\mathrm{I} .00$ (Ref) & $<0.001$ \\
\hline Civil servants & -0.345 & 0.145 & 0.601 & $0.71(0.17-2.12)$ & \\
\hline Business/service industries & 1.241 & 8.459 & 0.003 & $3.46(1.52-7.95)$ & \\
\hline Company employees & 0.912 & 4.443 & 0.074 & $2.49(0.98-4.33)$ & \\
\hline Unemployed & 1.873 & $|3.14|$ & $<0.001$ & $7.19(3.24-17.83)$ & \\
\hline \multicolumn{6}{|l|}{ Father's education level } \\
\hline Bachelor degree or above & & & & 1.00 (Ref) & $<0.001$ \\
\hline Junior college & 0.131 & 0.126 & 0.173 & $1.14(0.89-1.45)$ & \\
\hline High school & 0.588 & 2.463 & $<0.001$ & $1.80(1.29-2.50)$ & \\
\hline Junior high school or below & 2.852 & 7.629 & 0.005 & $17.33(2.53-1 \mid 8.99)$ & \\
\hline \multicolumn{6}{|l|}{ Mother's emotional stability } \\
\hline Unstable vs stable & 0.545 & 2.124 & 0.020 & $1.73(1.01-3.01)$ & 0.022 \\
\hline \multicolumn{6}{|l|}{ Father's emotional stability } \\
\hline Unstable vs stable & 1.042 & 6.109 & 0.001 & $1.83(1.28-6.28)$ & 0.001 \\
\hline \multicolumn{6}{|l|}{ Family type } \\
\hline Core family & & & & $\mathrm{I} .00($ Ref) & 0.393 \\
\hline Big family of multi-generation & -0.186 & 0.115 & 0.161 & $0.83(0.66-1.06)$ & \\
\hline Other (single parent, reorganization) & 0.495 & 1.352 & 0.323 & $0.64(0.50-5.37)$ & \\
\hline
\end{tabular}

Abbreviations: ADHD, attention-deficit/hyperactivity disorder; OR, odds ratio; $\mathrm{Cl}$, confidence interval; Ref, reference. 


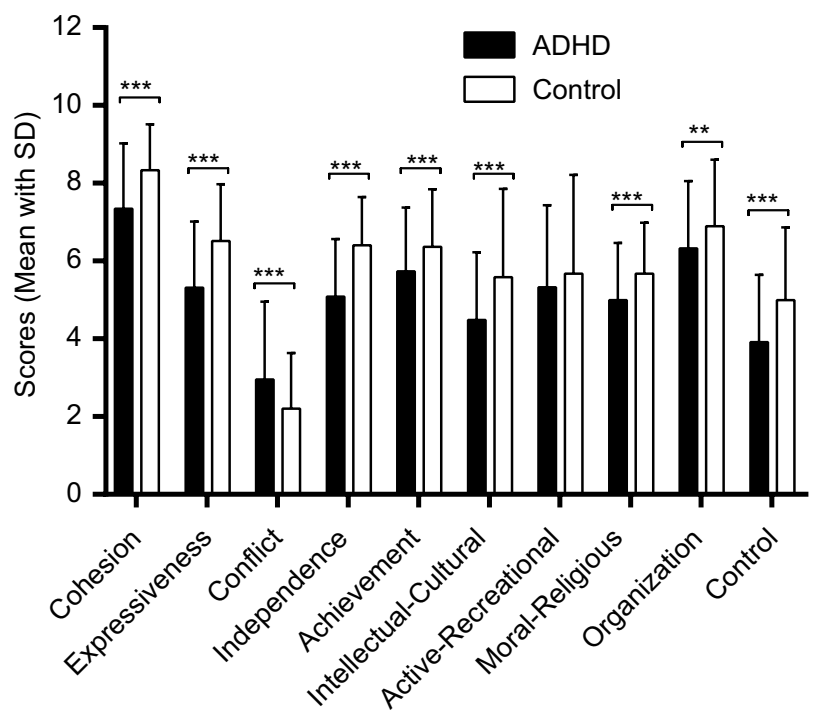

Figure I FES-CV scores of the ADHD and the control groups (mean $\pm \mathrm{SD}$ ). Notes: $* * P<0.01 ; * * * P<0.001$.

Abbreviations: ADHD, attention-deficit/hyperactivity disorder; FES-CV, Family Environment Scale Chinese Versions.

not significantly different between the two groups $(P>0.05)$. There was no significant difference of the scores between the younger and the older groups (data not shown).

CTRS test results indicate that the scores of conduct problem, hyperactivity, inattention, and CIH in ADHD group were higher than those of the control group (all $P<0.001$; Figure 2B). The conduct problem score of CTRS was higher in older group than that in younger group $(P<0.05$; data not shown).

In order to evaluate whether parent rating and teacher rating are consistent, Pearson correlation analysis was performed. The results suggest that the three dimensions (conduct problem, hyperactivity, and $\mathrm{CIH}$ ) are highly correlated with each other between CPRS and CTRS ( $r=0.834,0.803$, 0.872 , respectively; all $P<0.001$; Table S1).

\section{WFIRS-P}

According to the WFIRS-P test results and its dimensions analyses, the scores of family, learning and school, life skills, child's self-concept, social activities, risky activities, and total score were higher in the ADHD group than in the control group (all $P<0.001$; Figure 3 ). The scores of life skills in the high age groups were higher than those in the younger group $(P<0.05)$, and the scores of the other factors were not significantly different among the different age groups (data not shown).

\section{Results of field behavior observations among the ADHD and control groups}

The field behavior observations were performed in children's school environment by professionals, using class time (40

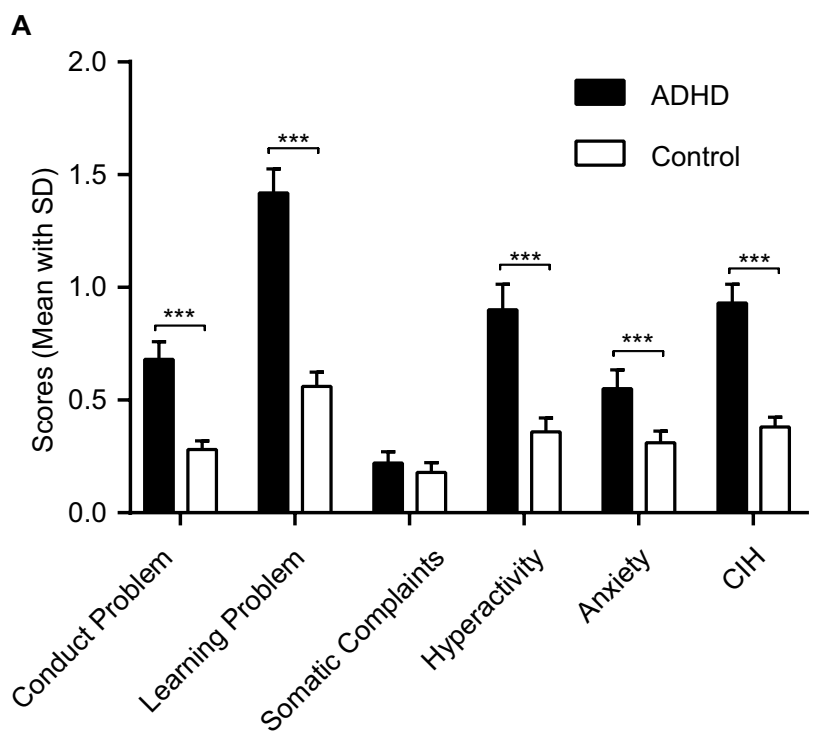

B

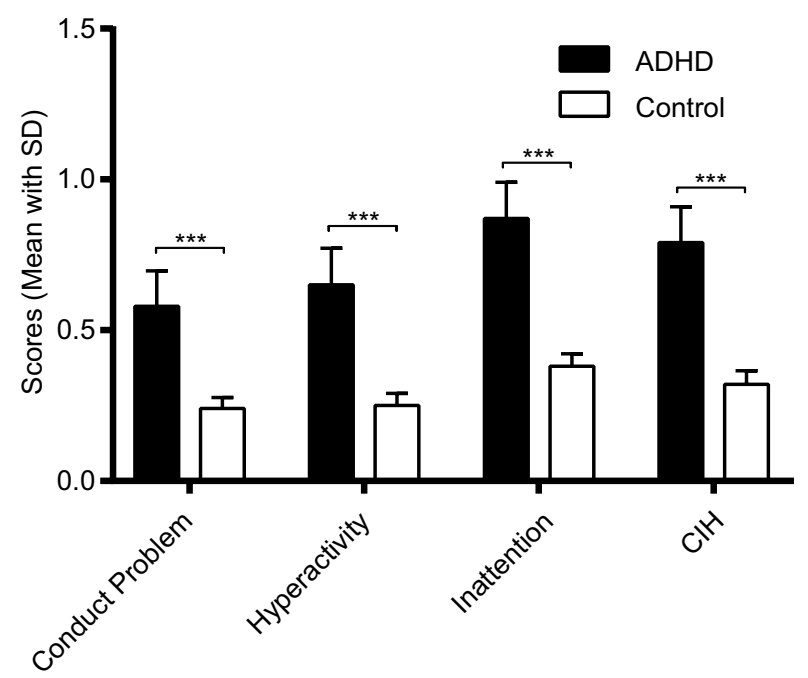

Figure 2 Conners' Children Behavior Scale scores between the ADHD and the control groups (mean $\pm \mathrm{SD}$ ).

Notes: (A) CPRS; (B) CTRS. $* * * P<0.001$.

Abbreviations: ADHD, attention-deficit/hyperactivity disorder; $\mathrm{ClH}$, Conners' Index of Hyperactivity; CPRS, Conners' Parent Rating Scale; CTRS, Conners' Teacher Rating Scale.

minutes) to finish. Field observation results show that compared with the control group, ADHD group had more positive rates of 12 identified behavior problems, as shown in Table 3 (all $P<0.001$ ).

\section{Discussion}

In our study, children with ADHD had worse family environment, lower FES-CV, higher CPRS, CTRS, and WFIRS-P scores compared with typically developing children. Children's ADHD were significantly affected by family status and family environmental factors. Family characteristics 
Table 3 Observed behaviors between the ADHD $(n=132)$ and the control $(n=138)$ groups

\begin{tabular}{|c|c|c|c|c|}
\hline Observed behaviors & ADHD, n (\%) & Control, n (\%) & $\chi^{2}$ & $P$-value \\
\hline Careless mistakes or sloppy writing & $122(92.4)$ & $39(28.3)$ & 115.38 & $<0.001$ \\
\hline Missing the examination questions & $105(79.5)$ & $17(12.3)$ & 132.11 & $<0.001$ \\
\hline Fugue states, procrastination & $58(43.9)$ & $9(6.5)$ & 50.63 & $<0.001$ \\
\hline $\begin{array}{l}\text { Cannot follow instructions, cannot complete } \\
\text { according to regulations }\end{array}$ & $39(29.5)$ & $2(1.4)$ & 41.35 & $<0.001$ \\
\hline Loss of tools or learning supplies & $27(20.5)$ & $2(1.4)$ & 25.42 & $<0.001$ \\
\hline Easily distracted by external stimuli & $130(98.5)$ & $29(21.0)$ & 167.25 & $<0.001$ \\
\hline Move around in their seats & $12 \mid(9 \mid .7)$ & $17(12.3)$ & 169.99 & $<0.001$ \\
\hline Leave the seat at will & $77(58.3)$ & $4(2.9)$ & 98.73 & $<0.001$ \\
\hline Random fiddle with the indoor objects & $35(26.5)$ & $9(6.5)$ & 19.77 & $<0.001$ \\
\hline $\begin{array}{l}\text { Unable to wait for alternate or difficult to } \\
\text { complete quietly }\end{array}$ & $21(15.9)$ & $2(1.4)$ & 18.10 & $<0.001$ \\
\hline Talkative, and disturb others & $81(6 I .4)$ & $4(2.9)$ & 106.91 & $<0.001$ \\
\hline Impatient & $51(38.6)$ & II (8.0) & 35.86 & $<0.001$ \\
\hline
\end{tabular}

Abbreviation: ADHD, attention-deficit/hyperactivity disorder.

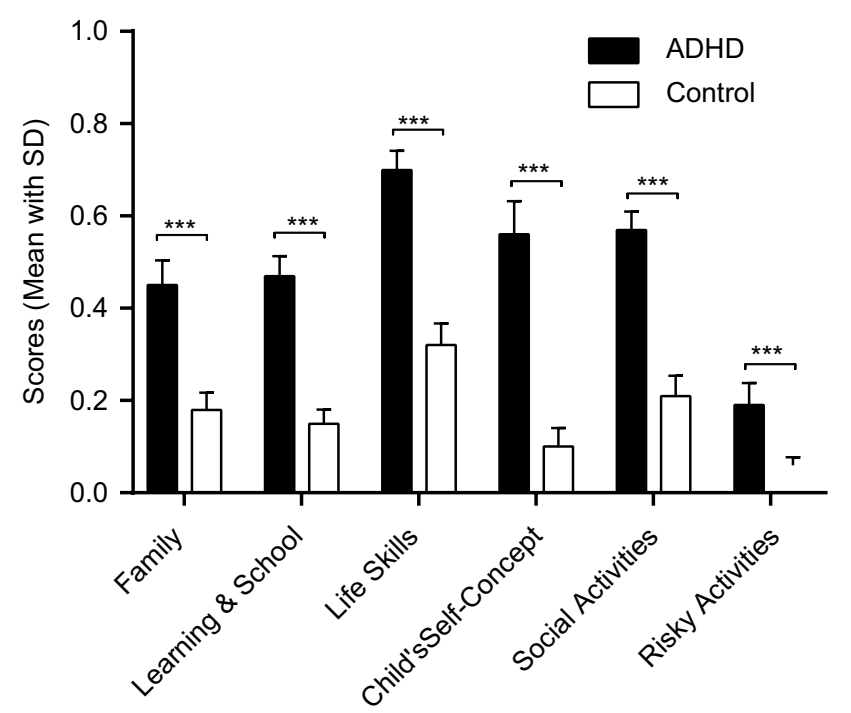

Figure 3 WFIRS-P scores of the ADHD and the control groups (mean \pm SD). Note: $* * * P<0.001$.

Abbreviations: ADHD, attention-deficit/hyperactivity disorder; WFIRS-P, Weiss Functional Impairment Scale-Parent.

especially parents' emotional unstability, lower education levels, and worse occupation status may increase ADHD risk in children. These factors were associated with their behavioral problems and development, and social functional impairments.

\section{Family status, family environmental factors, and ADHD}

In the unconditional logistic regression model, ADHD risk in children was increased with parents' worse educational level, occupational status, and emotional stability with trend, but not the family type. The education levels and occupational status of parents of children with ADHD were much lower and unemployed percentage was much higher compared with the controls, suggesting their families were in poverty or low SES. Some previous studies show strong support of our observations. ${ }^{26,27}$ Indeed, poverty is stressful and stress has been associated consistently with late onset of ADHD. ${ }^{28}$ In addition, low SES is often associated with poor family cohesiveness and frequent family conflicts ${ }^{29}$ and unfavorable prenatal conditions. ${ }^{30}$ Parents from these low SES families usually employed simple but rude methods in raising their children, including unreasonable scolding and beating, which would contribute to increased behavior problems in children. ${ }^{11}$ On the other hand, some of the parents were also plagued by ADHD in their own childhoods which would further aggravate ADHD in their children. $^{5}$

Our results from the family environment scale tests show that the ADHD group had lower cohesion, expressiveness, independence, achievement, intellectual-cultural, moralreligious, and organization and control scores than those of the control group, while the conflict score was higher. These results indicate that family environments for the children with ADHD lack emotional communication and emotional expression. In addition, children with ADHD usually had mood swings, lack unsustainable attention, and are unruly. Furthermore, parents of children with ADHD could also be adult ADHD patients and would have emotional control problems..$^{31}$ Therefore, all these factors would create constant family conflicts and develop a vicious cycle of hostility in the families. ${ }^{32}$ 


\section{Behavioral characteristics and impaired social function of ADHD}

The Conners' behavior scales were used to evaluate the behaviors of children. Because the subscales contained in the scale can directly reflect the common behavioral problems of children with ADHD, it is especially fit for the screening and evaluation of children with ADHD. ${ }^{33}$ Our results show that, whether at homes or in schools, the children with ADHD had serious problems with conduct, learning, hyperactivity/impulsivity, and anxiety, indicating the severity of their behavioral problems. With respect to age, the older group had more conduct problems than the younger one, indicating that proper and timely interventions are necessary.

Perhaps, the most serious aspect of ADHD is that it tends to be associated with social functional impairment. This not only endangers their social environment but also harms their health and life. In addition, they tend to exhibit executive function deficits, causing impairment in function in daily life ${ }^{34}$ and leading to negative effects on academic and occupational functions in adulthood. ${ }^{35}$

WFIRS-P is a social function assessment tool which is compiled based on the characteristics of ADHD disease and can reflect damage to ADHD children with social dysfunction. WFIRS-P can accurately reflect influences on six aspects of the social function: family, learning and school, life skills, child's self-concept, social activities, and risky activities; it can also be sensitive to reflect the efficacy of drug treatment. ${ }^{25,36}$ Our study shows that all the six aspects of the social function in ADHD group were significantly worse than those in the control group, suggesting that the impact of ADHD on school-age children was universal whether in school or at home. Our results also indicate that self-management and social interactions, and even many aspects such as life skills, have been significantly impaired. Our results are similar to that of a previous study. ${ }^{37} \mathrm{Com}-$ pared with the younger age group, the older group had more problems in life skills which would further increase with age due to symptoms in delay. Again, timely interventions are necessary and helpful..$^{38,39}$

Our FBOL was based on validated symptom items of DSM-5 diagnostic criteria and would objectively assess and quantify behavioral scores of children with ADHD. The results show that compared with control group, children with ADHD have more behavioral problems. These problems were from their impulsivity, inattention, and/or executive function deficits, making them hard to adapt school life and group activities, and to build positive interrelationships. It is observed that children with ADHD are often stigmatized and discriminated, so they had more inferiority, less confidence, and had more emotional problems.

\section{Strength and limitations}

There are lots of clinical reports on ADHD but most of them dealt with sampling of clinical samples. The current research is a case-control study on the basis of epidemiological investigation on ADHD among school-aged children in Shantou. Since the participants were screened out from public school children, our study would reflect the characteristics of children with ADHD in the general population. In addition, the controls were also from the same surveyed schools and classes; therefore, they provide valuable and valid comparison to our case population. Nevertheless, there exist some limitations in our study. Because this study was not a double-blind research, the observers knew partly in the field assessments which children were cases, which may lead to some bias. In addition, a total of 43 (25\%) parents of children with ADHD were unwilling to participate in the investigations, which resulted in the relatively low participation rate. But these children with ADHD who did not participate have no obvious different characteristics with others; the results should not be affected significantly. Another deficiency is that ours is a case-control survey which only focused on behavioral indicators. Our future study will employ laboratory methods, such as electrical physiology and brain imaging methods, to explore the possible pathogenesis of ADHD, and to further trace the evolution process, development track, and functional impairment of ADHD, so as to provide more precise guidance for clinical intervention.

\section{Conclusion}

Our results show that there are extensive and obvious behavioral problems and social functional impairments in ADHD children compared with typically developing children. Children with ADHD had lower scores in most subscales of family environment scale test except conflict subscale. ADHD risk also increased with family characteristics, especially parents' emotional unstability, lower education levels, and worse occupation status. Good family environment is conducive to the healthy growth of children. As the children with ADHD grew up, they showed more problems in conduct, school performance, and life skills. Therefore, our data clearly emphasize the need for specific and early detection as well as timely intervention to improve the prognosis of children with ADHD. 


\section{Abbreviations}

ADHD, attention-deficit/hyperactivity disorder; ASQ, Abbreviated Symptom Questionnaire; CIH, Conners' Index of Hyperactivity; CPRS, Conners' Parent Rating Scale; CTRS, Conners' Teacher Rating Scale; DSM-5, Diagnostic and Statistical Manual of Mental Disorders; FBOL, field behavior observation list; FES-CV, Family Environment Scale Chinese Versions; SES, social economical status; WFIRS-P, Weiss Functional Impairment Scale-Parent.

\section{Acknowledgments}

We are grateful to all the volunteers for participating in the present study. This work was supported by the Li Ka Shing Foundation, and Shantou Science and Technology Project (No. 121; No. 170817181930822).

\section{Disclosure}

The authors report no conflicts of interest in this work.

\section{References}

1. APA. Diagnostic and Statistical Manual of Mental Disorders, Fifth Edition (DSM-5). Washington DC: American Psychiatric Association; 2013.

2. Skounti M, Giannoukas S, Dimitriou E, Nikolopoulou S, Linardakis E, Philalithis A. Prevalence of attention deficit hyperactivity disorder in schoolchildren in Athens, Greece. Association of ADHD subtypes with social and academic impairment. Atten Defic Hyperact Disord. 2010;2(3): 127-132.

3. Huang Y, Zheng S, Xu C, et al. Attention-deficit hyperactivity disorder in elementary school students in Shantou, China: prevalence, subtypes, and influencing factors. Neuropsychiatr Dis Treat. 2017;13: 785-792.

4. Du Y, Li M, Jiang W, Li Y, Coghill DR. Developing the symptoms and functional impairment rating scale: a multi-dimensional ADHD scale. Psychiatry Investig . 2018;15(1):13-23.

5. Mordre M, Groholt B, Sandstad B, Myhre AM. The impact of ADHD symptoms and global impairment in childhood on working disability in midadulthood: a 28-year follow-up study using official disability pension records in a high-risk in-patient population. BMC Psychiatry. 2012;12(1):174.

6. Wilens TE, Faraone SV, Biederman J. Attention-deficit/hyperactivity disorder in adults. JAMA. 2004;292(5):619.

7. Thapar A, Cooper M. Attention deficit hyperactivity disorder. Lancet. 2016;387(10024):1240-1250.

8. Barkley RA, Murphy KR, Dupaul GI, Bush T. Driving in young adults with attention deficit hyperactivity disorder: knowledge, performance, adverse outcomes, and the role of executive functioning. $J$ Int Neuropsychol Soc. 2002;8(5):655.

9. Lecendreux M, Konofal E, Faraone SV. Prevalence of attention deficit hyperactivity disorder and associated features among children in France. J Atten Disord. 2011;15(6):516-524.

10. Dupaul GJ, Morgan PL, Farkas G, Hillemeier MM, Maczuga S. Academic and social functioning associated with attention-deficit/hyperactivity disorder: latent class analyses of trajectories from kindergarten to fifth grade. J Abnorm Child Psychol. 2016;44(7):1425-1438.

11. Weissenberger S, Ptacek R, Klicperova-Baker M, et al. ADHD, Lifestyles and comorbidities: a call for an holistic perspective - from medical to societal intervening factors. Front Psychol. 2017;8(85):454.

12. Biederman J. Attention-deficit/hyperactivity disorder: a selective overview. Biol Psychiatry. 2005;57(11):1215-1220.
13. Faraone SV, Perlis RH, Doyle AE, et al. Molecular genetics of attentiondeficit/hyperactivity disorder. Biol Psychiatry. 2005;57(11):1313-1323.

14. Thapar A, Cooper M, Jefferies R, Stergiakouli E. What causes attention deficit hyperactivity disorder? Arch Dis Child. 2012;97(3):260-265.

15. Holton KF, Nigg JT. The association of lifestyle factors and adhd in children. J Atten Disord. 2016:108705471664645.

16. du Prel Carroll X, Yi H, Liang Y, et al. Family-environmental factors associated with attention deficit hyperactivity disorder in Chinese children: a case-control study. PLoS One. 2012;7(11):e50543.

17. Ullsperger JM, Nigg JT, Nikolas MA. Does child temperament play a role in the association between parenting practices and child attention deficit/hyperactivity disorder? J Abnorm Child Psychol. 2016;44(1):167-178.

18. Klein RG, Mannuzza S, Olazagasti MAR, et al. Clinical and functional outcome of childhood ADHD 33 years later. Archives of General Psychiatry. 2012;69(12):1295.

19. Russell AE, Ford T, Williams R, Russell G. The association between socioeconomic disadvantage and attention deficit/hyperactivity disorder (ADHD): a systematic review. Child Psychiatry Hum Dev. 2016;47(3):440-458.

20. Wang XD, Wang XL, Ma H. Rating Scales for Mental Health. Beijing: Chinese Mental Health Journal; 1999.

21. Conners CK. Rating scales in attention-deficit/hyperactivity disorder: use in assessment and treatment monitoring. J Clin Psychiatry. 1998;59(Suppl 7(2)):24.

22. Gau SS, Soong WT, Chiu YN, Tsai WC. Psychometric properties of the Chinese version of the Conners' Parent and Teacher Rating ScalesRevised: Short Form. J Atten Disord. 2006;9(4):648-659.

23. Weiss MD. The unique aspects of assessment of ADHD. Primary Psychiatry. 2010;17:21-25.

24. Thompson T, Lloyd A, Joseph A, Weiss M. The Weiss Functional Impairment Rating Scale-Parent Form for assessing ADHD: evaluating diagnostic accuracy and determining optimal thresholds using ROC analysis. Qual Life Res. 2017;26(7):1879-1885.

25. Qian Y, du X-Q QS. Reliability and validity of the Chinese version of Weiss Functional Impairment Scale-Parent form for school age children. Chin Ment Health J. 2011;25(10):767-771.

26. Hong J, B-Q H, Wang L. The pupil's ADHD morbidity rate and their parents' education level and occupation. Modern Rehabilitation. 2001;5(17):32-33

27. Shen Y. Influence factor analysis of attention deficit hyperactivity disorder children and parental rearing patterns. J Clin Exp Med. 2007;6(11):115-116.

28. Grizenko N, Osmanlliu E, Fortier MĖ, Joober R. Increased risk of asthma in children with adhd: role of prematurity and maternal stress during pregnancy. J Can Acad Child Adolesc Psychiatry. 2015;24(2):109.

29. Santiago CD, Wadsworth ME, Stump J. Socioeconomic status, neighborhood disadvantage, and poverty-related stress: Prospective effects on psychological syndromes among diverse low-income families. $J$ Econ Psychol. 2011;32(2):218-230.

30. Woolf SH, Aron L, Dubay L, Simon S, Zimmerman E, Luk K. How are income and wealth linked to health and longevity? Urban Institute. 2015:1-22.

31. Park S, Hong KE, Yang YH, et al. Neuropsychological and behavioral profiles in attention-deficit hyperactivity disorder children of parents with a history of mood disorders: a pilot study. Psychiatry Investig. 2014;11(1):65-75.

32. Williamson D, Johnston C. Marital and coparenting relationships: associations with parent and child symptoms of ADHD. JAtten Disord. 2016;20(8):406-425.

33. Gianarris WJ, Golden CJ, Greene L. The Conners' Parent Rating Scales: a critical review of the literature. Clin Psychol Rev. 2001;21(7):1061-1093.

34. Sjöwall D, Roth L, Lindqvist S, Thorell LB. Multiple deficits in ADHD executive dysfunction, delay aversion, reaction time variability, and emotional deficits. J Child Psychol Psychiatry. 2013;54(6):619-627.

35. Miller M, Nevado-Montenegro AJ, Hinshaw SP. Childhood executive function continues to predict outcomes in young adult females with and without childhood-diagnosed ADHD. J Abnorm Child Psychol. 2012;40(5):657-668. 
36. Weiss MD, Gibbins C, Goodman DW, Hodgkins PS, Landgraf JM, Faraone SV. Moderators and mediators of symptoms and quality of life outcomes in an open-label study of adults treated for attentiondeficit/hyperactivity disorder. J Clin Psychiatry. 2010;71(4):381-390.

37. Banaschewski T, Johnson M, Lecendreux M, et al. Health-related quality of life and functional outcomes from a randomized-withdrawal study of long-term lisdexamfetamine dimesylate treatment in children and adolescents with attention-deficit/hyperactivity disorder. CNS Drugs. 2014;28(12):1191-1203.
38. Pritchard AE, Nigro CA, Jacobson LA, Mahone EM. The role of neuropsychological assessment in the functional outcomes of children with ADHD. Neuropsychol Rev. 2012;22(1):54-68.

39. Barkley RA. Global issues related to the impact of untreated attentiondeficit/hyperactivity disorder from childhood to young adulthood. Postgrad Med. 2008;120(3):48-59. 


\section{Supplementary materials}

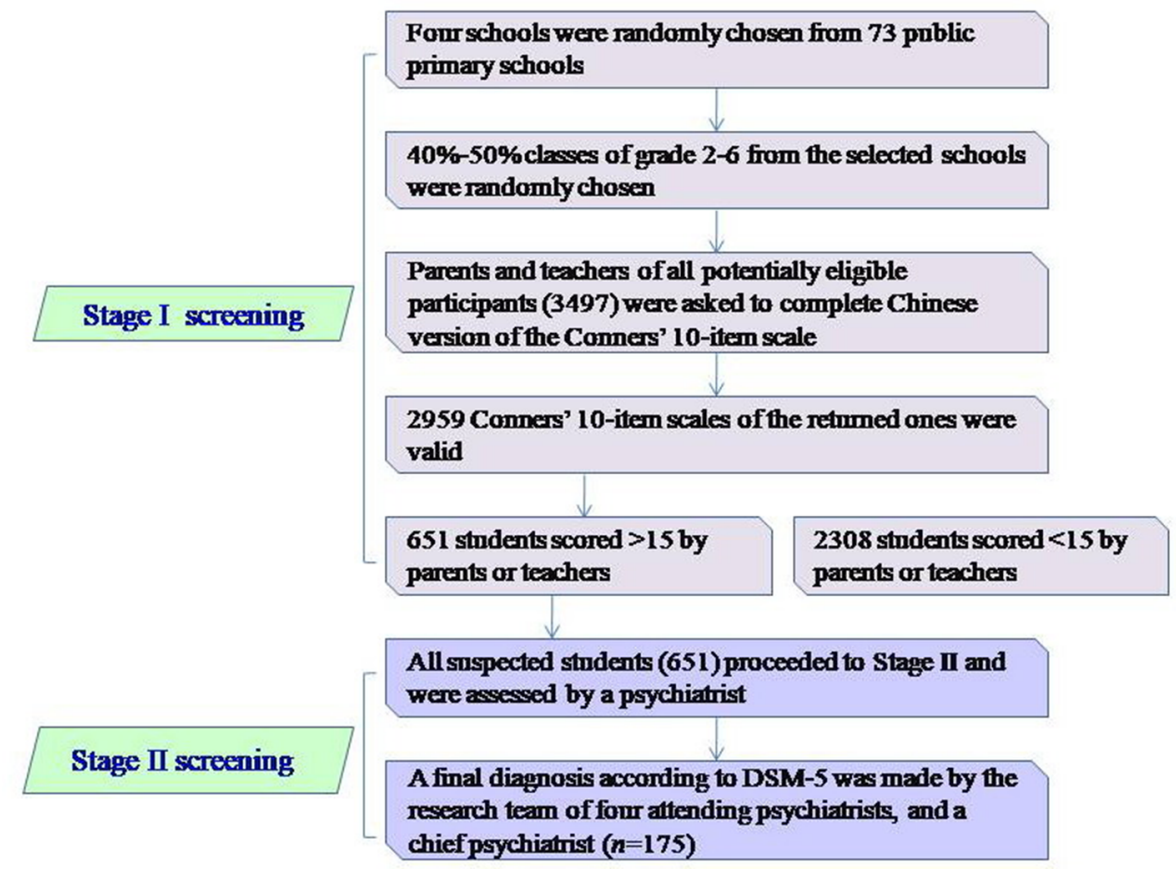

Figure SI Flowchart of the two-stage procedures of sampling participants and diagnosis of ADHD.

Abbreviation: ADHD, attention-deficit/hyperactivity disorder.

Table SI Correlation analyses between selected dimensions' score between CPRS and CTRS ( $\mathrm{n}=270$ )

\begin{tabular}{|l|l|l|}
\hline $\begin{array}{l}\text { Similar dimensions } \\
\text { of CPRS and CTRS }\end{array}$ & $\begin{array}{l}\text { Pearson correlation } \\
\text { coefficient }\end{array}$ & P-value \\
\hline Conduct Problem & 0.834 & $<0.00 \mathrm{I}$ \\
Hyperactivity & 0.803 & $<0.00 \mathrm{I}$ \\
$\mathrm{ClH}$ & 0.872 & $<0.00 \mathrm{I}$ \\
\hline
\end{tabular}

Abbreviations: $\mathrm{ClH}$, Conners' Index of Hyperactivity; CPRS, Conners' Parent Rating Scale; CTRS, Conners' Teacher Rating Scale.

\section{Publish your work in this journal}

Psychology Research and Behavior Management is an international, peerreviewed, open access journal focusing on the science of psychology and its application in behavior management to develop improved outcomes in the clinical, educational, sports and business arenas. Specific topics covered in the journal include: Neuroscience, memory and decision making; Behavior modification and management; Clinical applications; Business and sports performance management; Social and developmental studies; Animal studies. The manuscript management system is completely online and includes a very quick and fair peer-review system, which is all easy to use. Visit http://www. dovepress.com/testimonials.php to read real quotes from published authors. 